\title{
Fortalecedores e fragilizadores da amamentação na ótica da nutriz e de sua família*
}

\author{
Strengthening and weakening factors for breastfeeding from the \\ perspective of the nursing mother and her family \\ Fortalecedores y debilitadores de la lactancia bajo la óptica de \\ la lactante y su familia
}

Como citar este artigo:

Wagner LPB, Mazza VA, Souza SRRK, Chiesa A, Lacerda MR, Soares L. Strengthening and weakening factors for breastfeeding from the perspective of the nursing mother and her family. Rev Esc Enferm USP. 2020;54:e03563. doi: https://doi.org/10.1590/S1980-220X2018034303564

Lívia Perissé Baroni Wagner ${ }^{1,2}$

Verônica de Azevedo Mazza ${ }^{1}$

Silvana Regina Rossi Kissula Souza ${ }^{1}$

Anna Chiesa ${ }^{3}$

Maria Ribeiro Lacerda ${ }^{1}$

Larissa Soares ${ }^{1}$

* Extraído da dissertação: "Influências na amamentação: percepções, experiências familiares e apoio social", Universidade

Federal do Paraná, Programa de Pósgraduação em Enfermagem, 2017.

${ }^{1}$ Universidade Federal do Paraná, Programa de Pós-graduação em

Enfermagem, Curitiba, PR, Brasil

${ }^{2}$ Secretaria de Estado da Saúde do Paraná, Curitiba, PR, Brasil.

${ }^{3}$ Universidade de São Paulo, Escola de Enfermagem, Departamento de Enfermagem em Saúde Coletiva, São Paulo, SP, Brasil.

\section{ABSTRACT}

Objective: To describe the strengthening and weakening factors for breastfeeding. Method: This is a descriptive multiple case qualitative study, conducted in Curitiba, Parana, with members of 17 families with children between 6 and 12 months old, through semi-structured interview and construction of genograms, analyzed by the strategy of cross case synthesis. Results: 28 people participated in the study. Strengthening factors for breastfeeding were: the desire to breastfeed; child with facility for breastfeeding; mother with time available to the child; previous breastfeeding experience and family history of breastfeeding; the support and encouragement to breastfeed. Weakening factors were: negative expectations; the myth of weak milk; child's disease; maternal illness; negative experiences of the mother; the absence of family history of breastfeeding; lack of a support network. Conclusion: Breastfeeding is a family and social phenomenon. Therefore, practices that go beyond the mother-baby dyad are necessary. The care process should include the social and subjective dimension, strengthening the support network of nursing mothers, in order to obtain more satisfactory professional practices that promote breastfeeding.

\section{DESCRIPTORS}

Breast Feeding; Family; Social Support; Maternal-Child Nursing. 


\section{INTRODUÇÃO}

Estudo recente estima que o aumento do aleitamento materno no mundo pode prevenir anualmente 823.000 mortes de crianças e 20.000 mortes por câncer de mama nas mães. A crescente descoberta epidemiológica e biológica durante a última década expandiu os benefícios conhecidos da amamentação para mulheres e crianças ${ }^{(1)}$. Apesar disso, ainda são reportados baixos índices de amamentação no Brasil, no qual a prevalência do Aleitamento Materno Exclusivo (AME) em crianças menores de 6 meses foi de $41 \%$ e a duração média do AME foi de 54,11 dias $(1,8$ meses). Isto demonstra que mais da metade das crianças brasileiras não recebem o $\mathrm{AME}$ até os 6 meses ${ }^{(2)}$.

A fim de promover a amamentação, diversas ações político-sociais vêm sendo desenvolvidas no país nas últimas décadas. As primeiras iniciativas datam de 1981, com a criação do Programa Nacional de Incentivo ao Aleitamento Materno (PNIAM), e, desde então, observam-se avanços nos indicadores de AME no país ${ }^{(3)}$. Porém, cabe destacar que as políticas e estratégias desenvolvidas até então no Brasil para promoção, proteção e apoio ao aleitamento materno seguem incorporando concepções restritas e fragmentadas da função maternal da mulher em relação à amamentação, explorando superficialmente o papel da família, profissionais de saúde, sociedade e Estado nesse contexto. Sabe-se que o sucesso da amamentação não é uma decisão somente da mulher, mas uma responsabilidade coletiva e social ${ }^{(4)}$. A incidência e a duração da amamentação são influenciadas pelas intenções da mulher, condição de saúde da mãe e da criança, trabalho materno, apoio familiar, profissionais de saúde, questões culturais $^{(5)}$ e inclusive coabitar com o companheiro ${ }^{(6)}$.

Diante desse panorama, pesquisas reportam a necessidade de mais estudos que busquem desenvolver as habilidades maternas e profissionais para a manutenção da amamentação e que reforcem ações estratégicas de apoio às mulheres ${ }^{(7)}$. Pesquisas que extrapolam a dimensão biológica da amamentação podem impactar as políticas públicas de aleitamento materno por meio do reforço do papel social. Nesta perspectiva é necessário questionar: "Como atuam os elementos fortalecedores e fragilizadores da amamentação?" A fim de responder tal indagação, adotamos como objetivo deste estudo: descrever os elementos fortalecedores e fragilizadores da amamentação.

\section{MÉTODO}

\section{TIPO DE ESTUdo}

Trata-se de uma pesquisa com abordagem qualitativa, do tipo estudo de casos múltiplos com caráter descritivo pautado no referencial metodológico de $\mathrm{Yin}^{(8)}$.

\section{Cenário}

O estudo foi realizado no município de Curitiba/PR, em 10 Unidades de Saúde (US) com Estratégia Saúde da Família (ESF), sendo sorteada uma US por Distrito Sanitário, entre os 10 distritos do município.

\section{PopUlação}

Os participantes foram 28 familiares, de 17 famílias compostas de crianças com idade de 6 a 12 meses, residentes no município de Curitiba, atendidas pelas US sorteadas. Compuseram a amostra: 17 mães, sete pais e quatro avós.

\section{CRITÉRIOS DE SELEÇÃo}

Foram adotados os seguintes critérios de inclusão: ser mãe, pai ou familiar de lactente com idade de 6 a 12 meses, em aleitamento materno na alta hospitalar da maternidade; e família cadastrada na US sorteada. Os critérios de exclusão foram: ser menor de 18 anos; e ter dificuldade de comunicação. Foi garantido aos integrantes do estudo o direito à confidencialidade das informações e ao anonimato, sendo utilizadas siglas para a sua identificação. Os integrantes do estudo não conheciam a pesquisadora previamente, tendo sido informados sobre a formação da pesquisadora, o interesse no tema e os objetivos da pesquisa. Aqueles que concordaram voluntariamente em participar assinaram o Termo de Consentimento Livre e Esclarecido e foram informados sobre a possibilidade de desistência. A amostra foi definida por saturação dos dados, o que esteve na dependência do alcance do objetivo e compreensão do fenômeno estudado, independentemente da quantidade de entrevistas.

\section{Coleta de Dados}

A coleta de evidências foi realizada no período de março a abril de 2017 por meio de entrevista. Foram elaborados, pelas pesquisadoras, instrumentos semiestruturados para a mãe, o pai, as mulheres e os demais membros da família. $\mathrm{O}$ instrumento foi composto da caracterização dos entrevistados (estado civil, escolaridade, histórico obstétrico, pré-natal, trabalho, renda), de caracterização da criança-índice (data de nascimento, idade gestacional, local de nascimento, complicações) e de perguntas relacionadas à amamentação. Estas abordaram as expectativas anteriores ao nascimento relativas à amamentação, à experiência com amamentação, à participação da família, aos motivos para manter ou interromper a amamentação, às pessoas e aspectos que influenciaram este processo e ao papel dos profissionais de saúde.

A primeira entrevistada da família foi a mãe do lactente e posteriormente outros membros da família que tiveram participação na amamentação. Todas as entrevistas foram realizadas pela mesma pesquisadora nas dependências da US, no domicílio da família ou por contato telefônico. A duração média das interlocuções foi de 15 minutos, as quais foram gravadas em áudio e transcritas posteriormente. Depois da transcrição, as entrevistas foram devolvidas aos participantes por e-mail ou mensagem de Whatsapp ${ }^{\circledR}$, para correção e revisão, se necessário.

O genograma foi utilizado para a análise da estrutura e das relações familiares, pois este instrumento possibilita a representação gráfica da família por meio de símbolos, mostrando suas características, relacionamentos e importantes eventos vividos pelas gerações ${ }^{(9)}$. Em nosso estudo, os genogramas foram construídos durante as entrevistas juntamente com as mães e foram utilizados para representar o contexto 
familiar da nutriz na amamentação, a fim de complementar e orientar a análise individual dos relatos. Adotou-se a nutriz como pessoa-índice do genograma, e por meio de símbolos foram representadas a família referida, a qualidade dos relacionamentos familiares e as mulheres da família que tiveram experiência com amamentação maior ou igual a 6 meses e aquelas com amamentação por menos de 6 meses.

\section{AnÁlise E TRATAMENTO dOS DADOS}

A família foi considerada a unidade de análise do caso e Estratégia Analítica da Síntese de Casos Cruzados foi utilizada para análise. Por definição, esta é uma técnica que se aplica à análise de estudo de casos múltiplos, buscando explorar se os casos se replicam ou contrastam uns em relação aos outros ${ }^{(8)}$.

Desta forma, inicialmente foram realizadas a leitura individual de cada entrevista, a construção dos códigos iniciais pelo pesquisador, a elaboração de quadro-síntese para cada família estudada e posterior comparação entre elas. Depois disso, os dados foram organizados no software MAXqda ${ }^{\circledR}$ para agrupar as falas em categorias temáticas e análise detalhada. Ressalta-se que ${ }^{(8)}$ os registros palavra por palavra consistem em apenas uma parte da série de evidências de um estudo de caso, sendo necessário, para um conjunto diversificado de evidências, desenvolver suas próprias estratégias analíticas. Neste estudo, foi utilizada como parte da estratégia analítica a construção de mapas mentais que continham as categorias. Depois da finalização das categorias no software, foi realizada a síntese de casos cruzados entre as famílias do estudo, por meio da elaboração de um novo quadro-síntese com as principais informações obtidas na análise dos dados. Nesse momento utilizou-se do genograma para comparar os dados da avaliação estrutural de cada família, observando-se como as histórias e os antecedentes familiares de amamentação se replicavam e contrastavam entre si e relacionando-os com as categorias que emergiram das entrevistas.

\section{Aspectos éticos}

A pesquisa preservou os preceitos éticos de participação voluntária, esclarecida e consentida, anonimato e sigilo dos participantes, segundo a Resolução n.o 466/2012, do Conselho Nacional de Saúde. O projeto foi aprovado pelo Comitê de Ética em Pesquisa do Setor de Ciências da Saúde da Universidade Federal do Paraná, sob o Parecer n. ${ }^{\circ}$ 1.766.141, em 07 de outubro de 2016.

\section{RESULTADOS}

O perfil dos participantes do estudo foi: mães com idade entre 19 e 42 anos, em união estável, com segundo grau completo/incompleto, mais de três filhos, a maioria não trabalhava fora de casa; pais com idade entre 25 e 52 anos, com primeiro grau incompleto; avós com idade entre 43 e 77 anos, com primeiro grau incompleto; e renda média familiar de um a dois salários mínimos.

Por meio da análise de dados das 28 entrevistas, foram gerados no software 993 códigos. As categorias temáticas que emergiram dos dados foram: Percepção de Amamentação (180 códigos), Condição Materna (136 códigos), Condição da Criança (178 códigos), Experiência Familiar (159 códigos) e a Rede Social de Apoio (340 códigos). Na Figura 1, são apresentadas as categorias temáticas dos elementos influenciadores da amamentação, e, a seguir, apresentado o corpus do processo analítico:

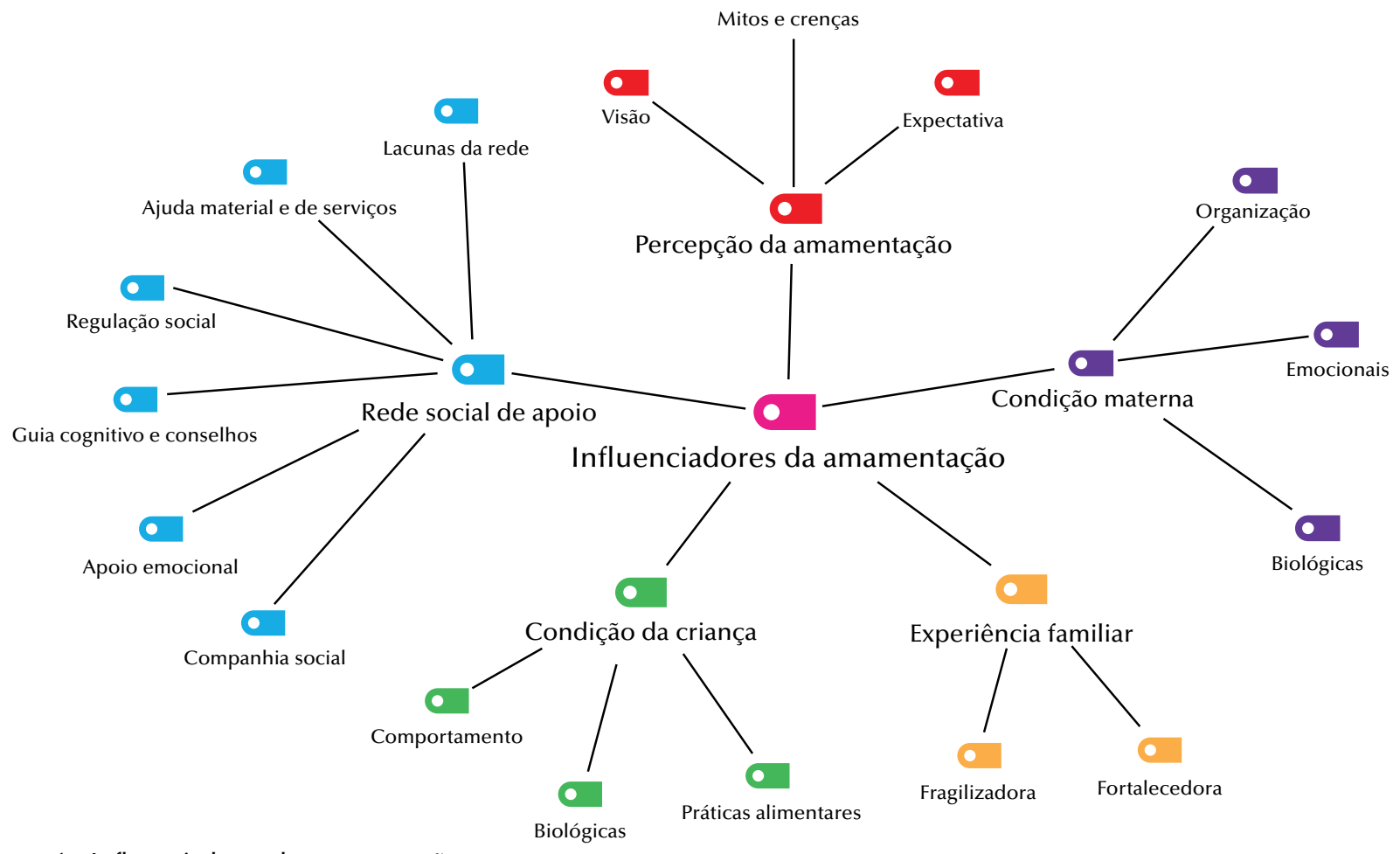

Figura 1 - Influenciadores da amamentação. 
A percepção de amamentação foi descrita pelas expectativas em sua maioria positivas, evidenciadas pela vontade de amamentar. A visão dos familiares é substancialmente fortalecedora, pois relaciona a amamentação como necessária para a criança, protege de doenças e alergias, mantém a saúde, além de acalmar e promover o vínculo.

(...) eu não via a hora de amamentar de novo (M 4).

(...) meus filhos eu amamentava para ver eles bonitos, formosos, porque tinha bastante leite, nossa muito leite (A 3).

(...) bom, é até 6 meses, para a criança já ganhar anticorpos para proteger das doenças $(\mathrm{P} 14)$.

A expectativa e a visão das famílias que atuaram como fragilizadoras estavam relacionadas à falta de leite e dificuldade para amamentar. Reforçando esse discurso, foram evidenciados os mitos e as crenças relacionados à percepção do leite fraco, a dúvida se o leite estava sustentando e sendo suficiente para o bebê.

(...) eu imaginava primeiramente eu não ia ter leite, eu imaginava que eu não ia conseguir amamentar ela [filha], como ninguém da minha familia conseguiu, isso me influenciou para mim pensar só negativo (M 13).

(...) [o leite materno] não estava sustentando, porque o NAN é forte, aí depois isso não sustentava ela e eu tive que dar o Nestogeno (M 12).

Com relação à Condição da criança, evidenciou-se que crianças saudáveis e as que tiveram facilidade para mamar obtiveram maior sucesso na amamentação em relação àquelas que foram submetidas a práticas alimentares com uso de oferta fórmula lácteas.

(...) A neném nunca teve assim dificuldade de mamar (P 13).

(...) Dos três dias que fiquei no hospital, ele só mamou o complemento (M 12).

O comportamento de choro excessivo da criança atuou como elemento fragilizador na amamentação, assim como as condições biológicas de doença, prematuridade e dificuldade para o ganho de peso, que influenciaram negativamente $o$ desfecho da amamentação.

(...) Eu parei de dar mamá e ela ainda continuava chorando de madrugada, a noite inteira (M 2).

(...) Ele foi internado dai eles deram leite NAN para ele, dai ele não quis mais o peito (M 8).

No que diz respeito à Condição materna, os discursos apresentaram que era necessária uma organização da rotina e do tempo da nutriz para que ela conseguisse amamentar e que, apesar de trabalhar fora, algumas mulheres conseguiram manter a amamentação.

(...) Eu trabalhava, ai eles [filhos] ficavam na creche, ai chegava do serviço ia lá e amamentava os dois, colocava um aqui outro aqui e os dois mamavam, sem problema. (M 10).

A condição biológica de doença materna, problemas com a mama durante a amamentação, seja por fissuras, sangramento ou mesmo a percepção de leite insuficiente foram fragilizadores.

(...) Secou o leite, eu não tinha o biquinho do peito e aí como eu tentava dar de mamar e não conseguia, começou a secar, ai quando eu procurei o posto já não tinha mais [leite] (M 7).

Nesse mesmo sentido, as condições emocionais de ansiedade e nervosismo tiveram associação com o desmame precoce:

(...) passar nervosismo e saber que o nervosismo acaba acarretando muitas coisas pra você, inclusive a falta do leite, o leite secar eu sei que é um pouco disso (M 3).

A Experiência familiar com a amamentação, identificada por meio da análise dos genogramas (Figura 2) e das entrevistas, evidenciou que a experiência positiva anterior da nutriz com a amamentação de outros filhos foi um dos aspectos que fortaleceram a amamentação.

(...) eu amamentei meus filhos, os meus mais velhos eu amamentei até 1 ano, o segundo até quase 10 meses, ele mesmo soltou por conta própria, a terceira foi até 3 anos e 4 meses (M 9).

Ter membros da família que amamentaram contribuiu positivamente para uma amamentação mais eficaz e duradoura, enquanto a falta de experiência, vivências negativas e ausência de história familiar de amamentação contribuíram para um contexto de dificuldades na amamentação que acarretaram o desmame.

(...) Na minha família quando elas ganham neném eu sempre vejo elas amamentarem até um certo tempo, eu nunca vi elas darem mamadeira (M 7).

(...) Quando ele [bebê] estava sugando, ela [esposa] sentia alguma dificuldade, talvez seja por essas questôes que eu te falei, de não ter experiência nem nada assim, ser o primeiro filho (P 3).

A história familiar de amamentação pode ser visualizada por meio da representação do genograma da família F9 (Figura 2), no qual evidenciamos a mãe e as cunhadas que amamentaram por 6 meses ou mais. A análise desta representação faz-nos considerar que as mulheres que amamentaram nesta família atuaram como referências de amamentação para a nutriz e, juntamente com o relacionamento muito próximo com sua mãe que amamentou, exerceram papel fortalecedor para o incentivo da amamentação. Mesmo que a sogra não tenha amamentado, o fato de ter um relacionamento conflituoso com ela pode ter contribuído para que a experiência dela não tenha influenciado sua decisão de amamentar. 


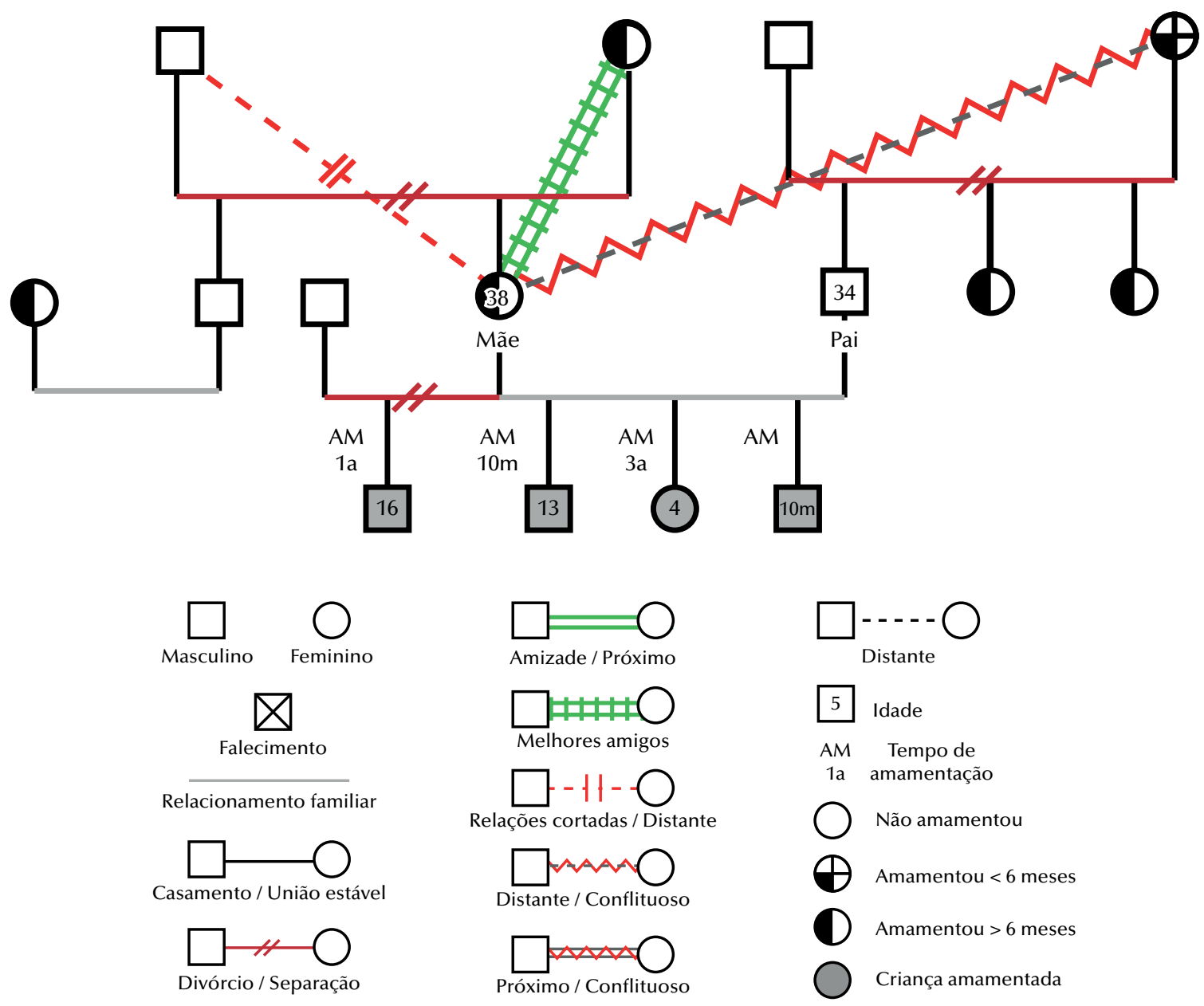

Figure 2 - Genogram of Family F9.

A Rede social de apoio da nutriz e de sua família foi identificada como fortalecedora quando exerceu funções de: apoio material e de serviços, por meio do cuidado com outros filhos, na ajuda nos afazeres domésticos e no auxílio direto na amamentação, principalmente pelo pai e avó materna da criança; guia cognitivo e de conselhos, pelo suporte ofertado por enfermeiros e outros profissionais de saúde à amamentação; companhia social, por meio da presença e o apoio emocional com o incentivo e suporte.

(...) Falava para ela [filha nutriz] que o leite do seio é a melhor vitamina que tem para criança, não precisa nem dar água para criança quando está mamando no seio (A 8).

(...) Eles orientavam lá na maternidade (...) explicavam direito como pegar para colocar a mama na boca dele, essas coisas (M $15)$.

(...) meu marido, ele é meu companheiro, ele é meu amigo, sabe? Ele tem que saber o que tá se passando, se eu acho que não está bom uma coisa ele me ajuda, ele que me ajuda sempre (M 10).

Por outro lado, em algumas situações, a rede desempenhou o papel de regulação social ao realizar práticas impositivas para a amamentação, atuando como um desestímulo para a nutriz.

(...) Meu marido me enchia muito o saco para eu dar de mamar (...) e eu não conseguia, ele nunca me entendia (...) não me encorajava na verdade, só me deixava pior (M 2).

\section{(...) Eu vivia de hospital em hospital, mas eu não tive nenbuma} orientação (M 13).

Evidencia-se que as lacunas da rede de apoio demonstradas pela falta de suporte e incentivo para a amamentação e pela ausência de orientações da rede fragilizam o contexto de amamentação.

\section{DISCUSSÃO}

A percepção sobre amamentação é uma construção de conhecimentos advindos dos sentidos e da memória e varia conforme a origem de suas informações, condições sociais e econômicas, cultura, crenças, emoções, habilidades, necessidades e objetivos ${ }^{(10)}$. Estudo realizado com mulheres mexicanas residentes nos Estados Unidos da América identificou que a bagagem cultural é fundamental na decisão de amamentar ${ }^{(11)}$. Neste estudo, identificamos que, em geral, as famílias têm uma boa visão da amamentação, referindo-a como algo que fornece saúde, proteção e vínculo, porém, algumas puérperas referiram que durante a gestação criaram expectativas relacionadas à não produção de leite $\mathrm{e}$ não conseguir amamentar. Isto nos fez inferir que somente conhecer as vantagens do aleitamento materno não fornece à mulher a certeza de que conseguirá amamentar, levando-nos a entender que existem mais elementos que influenciam a amamentação do que somente a percepção. 
Durante as entrevistas foram descritas a percepção de pouco leite e o mito do leite fraco. A alegação de pouco leite é uma das queixas mais comuns para explicar o oferecimento de fórmulas lácteas, sendo muitas vezes relacionada à insegurança da mãe sobre sua produção de leite em quantidade adequada para a necessidade da crianç ${ }^{(12)}$. De forma semelhante, o mito do leite fraco está relacionado à percepção das famílias da fome e choro da criança, como se o leite não a estivesse sustentando ${ }^{(13)}$.

Com relação às práticas alimentares da criança, o passo 6 da Iniciativa Hospital Amigo da Criança (IHAC) recomenda que os recém-nascidos recebam somente leite materno até os 6 meses e que as fórmulas lácteas sejam ofertadas exclusivamente quando há prescrição médica ${ }^{(14)}$. Porém, a realidade evidenciada atualmente é que diversos pediatras não estão envolvidos no contexto da IHAC e muitas vezes recomendam sem discriminação o uso de leites artificiais ${ }^{(12)}$. O comportamento de choro excessivo dos bebês é uma causa comum para o desmame, pois está frequentemente relacionado ao estresse dos pais, à ansiedade e depressão materna. Famílias com bebês que choram excessivamente têm uma tendência maior a desmamarem precocemente, devido às percepções de fome e da insuficiência de leite ${ }^{(13)}$.

A condição biológica da criança é um aspecto que também influencia a amamentação, pois a criança saudável tem melhores condições de ser amamentada, enquanto aquela que necessita de cuidados especiais e internação pode ter a amamentação prejudicada. O início tardio da amamentação e o afastamento de mãe e bebê durante a permanência na Unidade de Terapia Intensiva Neonatal foram relacionados a desfechos comprometedores para a amamentação, principalmente quando são ofertadas fórmulas lácteas ${ }^{(15-16)}$.

Para as entrevistadas, a organização da rotina da mãe para com a criança demonstrou-se essencial para a manutenção da amamentação, principalmente para aquelas que trabalhavam fora. Outro estudo apontou a relação do trabalho materno com o desmame precoce e a introdução de leite artificial na dieta da criança ${ }^{(5)}$. Em contrapartida, nossa pesquisa identificou nutrizes que conseguiram manter a amamentação mesmo trabalhando fora, porém a dificuldade encontrada foi de conseguir manter a amamentação de forma exclusiva. Apesar de existirem no Brasil recentes políticas de extensão da licença-maternidade de 4 para 6 meses ${ }^{(17)}$, sabe-se que este não é um direito garantido para todas as mães. Muitas crianças têm o AME prejudicado porque as mães têm de voltar a trabalhar antes dos 6 meses, o que demonstra a fragilidade existente para a manutenção da exclusividade e a necessidade de ampliação destas políticas públicas.

A doença materna foi elencada pelas famílias como um motivo para a interrupção da amamentação, pois esteve relacionada ao afastamento entre mãe e bebê e ao uso de medicamentos contraindicados na amamentação. Ressalta-se que, na necessidade do tratamento, cabe ao profissional de saúde buscar uma droga que seja compatível com a amamentação ${ }^{(18)}$ e possibilitar a permanência de mãe e bebê juntos durante a internação. Os traumas mamilares e a dor na amamentação, citados pelos participantes da pesquisa, são problemas comuns nos primeiros meses pós-parto que fragilizam a amamentação e podem fazer com que a mulher perca a vontade de amamentar ${ }^{(19-20)}$. Outros aspectos prejudiciais são a ansiedade e o estresse pós-parto, pois influenciam a lactação devido à ação de hormônios que afetam a produção e a composição do leite por meio de respostas psicológicas ao estresse ${ }^{(21)}$. Evidência sugere que puérperas ansiosas têm menor chance de amamentar e maior possibilidade de iniciar o oferecimento de fórmulas infantis ${ }^{(22)}$.

A experiência pessoal e a história positiva de amamentação na família, identificadas por meio da análise dos genogramas familiares, foram consideradas elementos fortalecedores para as nutrizes desta pesquisa. Investigação realizada na Escócia demostra que a experiência pessoal exitosa da mulher na amamentação de outros filhos contribui para deixá-la mais segura com o desempenho dessa prática ${ }^{(23)}$. Conhecer alguém que amamentou por mais de 1 mês ou ter sido amamentada quando criança são fatores relevantes para diminuir os índices de desmame precoce ${ }^{(23-25)}$. Por outro lado, em contextos nos quais não houve antecedentes familiares de amamentação a tendência é que menos mulheres dessa família amamentem ${ }^{(26)}$.

Neste sentido, o uso do genograma possibilitou a identificação de mulheres que amamentaram e que desmamaram precocemente na família. A utilização deste instrumento com este enfoque pode contribuir para o trabalho das equipes de Estratégia de Saúde da Família, como uma ferramenta de promoção ao aleitamento materno. Ao identificar uma família com história negativa de amamentação, o profissional de saúde que acompanha o pré-natal pode realizar um monitoramento mais próximo da gestante e futura nutriz, a fim de compensar as lacunas existentes na família, proporcionando o fortalecimento e ampliação da rede de apoio. Assim como ao identificar antecedentes familiares positivos de amamentação pode estimular a participação da família no pré-natal e puerpério, a fim de incentivar a nutriz para amamentar.

Ao tratar da rede de apoio na amamentação, parece que uma das principais influências na experiência da mulher com relação à alimentação de seu filho é a habilidade da família em apoiar a amamentação ${ }^{(27)}$. As nutrizes desta pesquisa reconheceram o importante papel do companheiro na divisão de tarefas da casa. Este dado corrobora outra pesquisa que evidenciou as atividades em que as nutrizes precisavam de ajuda, sendo citados os afazeres domésticos, os cuidados com o bebê e outros filhos e o preparo das refeições ${ }^{(24)}$.

Os enfermeiros foram elencados nesta pesquisa como auxiliares diretos da amamentação por meio de massagens, ordenha das mamas e orientações. Revisão de literatura reforça que o principal papel dos profissionais de saúde é fornecer conselhos, orientações, informações sobre aleitamento materno, esclarecimento de mitos, incentivo da amamentação até os 6 meses, além da ajuda direta na amamentação ${ }^{(12)}$. Estudos demonstraram que as orientações durante o pré-natal foram um fator de proteção para a amamentação( ${ }^{(28-29)}$. Mesmo com essa evidência, algumas famílias deste estudo vivenciaram a ausência de orientações adequadas nas US e nas maternidades durante o pré-natal.

Há evidências de que ao iniciar a amamentação é importante que a mulher receba apoio verbal, por meio de elogios 
e incentivo, a fim de estimular a nutriz. As avós maternas são referidas como pessoas fundamentais no processo de amamentação. Os parceiros são vistos como indispensáveis. Metassíntese identificou que mães que amamentam têm maior suporte social de sua rede do que mães que ofertam fórmulas lácteas para seus filhos ${ }^{(30)}$. Há relatos de que a presença empática de pessoas reduz o impacto do estresse e colabora para menores níveis de ansiedade, depressão e dor física ${ }^{(27)}$.

Quando a família se demonstra crítica com a decisão da mulher de amamentar, isso frequentemente afeta a habilidade de a mulher buscar suporte da família, bem como os seus sentimentos em relação a seus membros ${ }^{(28)}$. A identificação precoce de lacunas no apoio familiar pode permitir o desenvolvimento de outros vínculos na rede social, a fim de compensar e permitir que a mulher possa encontrar referência e suporte para amamentação ${ }^{(23)}$. Percebe-se a necessidade da ampliação da dimensão positiva da amamentação, a fim de que as famílias recebam o apoio de que necessitam durante este processo. Portanto, é relevante que exista um fortalecimento de práticas promotoras que permitam a efetivação e a manutenção da amamentação. É preciso que haja políticas públicas implementadas nos serviços de saúde que sejam efetivas e que fortaleçam a rede social de apoio das nutrizes, pois não é possível deixar a amamentação como responsabilidade exclusiva desta família.

Ademais, reconhecem-se as limitações deste estudo, por ser realizado em uma região circunscrita, ou seja, possuidora de cultura e comportamentos próprios, portanto, não é possível afirmar que a circunstância aqui apresentada possa se repetir ou ser aplicável em outros contextos. Abre-se a perspectiva para novos estudos desta natureza, pois existem pesquisas que elencam os elementos fragilizadores da amamentação, mas ainda existem poucas evidências de ações eficientes para o fortalecimento da amamentação.

\section{CONCLUSÃO}

As famílias tiveram como elementos fortalecedores da amamentação: a percepção da amamentação como algo importante e necessário para a criança; a criança saudável e com facilidade para mamar; a mãe com disponibilidade de tempo para a criança; a experiência anterior da nutriz com a amamentação de outros filhos; os antecedentes familiares de amamentação; o apoio e o incentivo para amamentar, principalmente do pai e avó materna; e o suporte dos profissionais de saúde, por meio de orientação e apoio.

Enquanto os elementos fragilizadores da amamentação foram: as expectativas negativas; o mito do leite fraco; o choro excessivo, a prematuridade e as internações da criança; a ansiedade e as afecções maternas; a falta de experiência e as vivências negativas da mãe; a ausência de antecedentes familiares de amamentação; a rede de apoio com práticas impositivas; e a falta de apoio e suporte. Na presença destes elementos fragilizadores é necessário que a nutriz receba, além do apoio familiar, o apoio de profissionais e de serviços de saúde amparados por políticas institucionais efetivas e fortalecedoras, a fim de poder obter sucesso na amamentação.

O processo de cuidado na amamentação deve extrapolar o binômio mãe-filho, trazendo uma rede de apoio fortalecedora, tanto no âmbito familiar como no dos profissionais de saúde, em especial da enfermagem. Este cuidado deve envolver a dimensão subjetiva, na qual consta o desejo de amamentar, a concepção de amamentação, a experiência da mulher e a história familiar de amamentação. É preciso ter atenção especial às mulheres e suas famílias para a construção familiar do processo de amamentação desde o pré-natal, trazendo suas histórias e experiências exitosas. A compreensão da dimensão social e subjetiva pode redirecionar o processo de cuidado para práticas profissionais mais satisfatórias e promotoras da amamentação.

$\mathrm{Na}$ realização desta pesquisa, considera-se inovadora a utilização do genograma para contribuir para a compreensão da estrutura e contexto familiar. Tendo em vista que o uso deste instrumento com foco na história familiar da amamentação não é comum, destaca-se que enfermeiros e médicos da Estratégia de Saúde da Família podem ser beneficiados ao utilizá-lo com este enfoque, pois contribui para uma visão mais aprofundada da família, possibilitando intervenções direcionadas às lacunas encontradas. Este estudo pode servir de subsídio para a formulação de novas políticas públicas que apresentem uma visão mais ampla, por meio da inclusão da família em todo o processo de amamentação.

\section{RESUMO}

Objetivo: Descrever os elementos fortalecedores e fragilizadores da amamentação. Método: Pesquisa com abordagem qualitativa do tipo estudo de casos múltiplos com caráter descritivo, realizado no município de Curitiba, Paraná, com membros de 17 famílias compostas de crianças de 6 a 12 meses, por meio de entrevista semiestruturada e construção de genograma, analisados pela estratégia de síntese de casos cruzados. Resultados: Participaram do estudo 28 membros. Foram fortalecedores da amamentação: a vontade de amamentar; criança com facilidade para mamar; mãe com disponibilidade de tempo para a criança; experiência anterior da nutriz e antecedentes familiares de amamentação; o apoio e o incentivo para amamentar. Os fragilizadores da amamentação foram: expectativas negativas; o mito do leite fraco; a doença da criança; as afecções maternas; vivências negativas da mãe; a ausência de antecedentes familiares de amamentação; a falta de apoio e suporte da rede. Conclusão: Amamentar é um fenômeno familiar e social, portanto são necessárias práticas promotoras que extrapolem o binômio mãe-bebê. No processo de cuidar deve-se buscar o envolvimento da dimensão social e subjetiva, por meio do fortalecimento da rede de apoio das nutrizes, a fim de obterem-se práticas profissionais mais satisfatórias e promotoras da amamentação.

\section{DESCRITORES}

Aleitamento Materno; Família; Apoio Social; Enfermagem Materno-Infantil.

\section{RESUMEN}

Objetivo: Describir los elementos fortalecedores y debilitadores de la lactancia. Método: Investigación con abordaje cualitativo del tipo estudio de casos múltiples con carácter descriptivo, llevado a cabo en el municipio de Curitiba, Paraná, con miembros de 17 familias compuestas de niños de 6 a 12 meses, mediante entrevista semiestructurada y construcción de genograma, analizados por la 
estrategia de síntesis de casos cruzados. Resultados: Participaron en el estudio 28 miembros. Fueron fortalecedores de la lactancia: el deseo de amamantar; niño con facilidad para mamar; madre con disponibilidad de tiempo para el niño; experiencia previa de la lactante y antecedentes familiares de lactancia; el apoyo y el incentivo para amamantar. Los debilitadores de la lactancia fueron: expectativas negativas; el mito de la leche flaca; la enfermedad del niño; las afecciones maternas; vivencias negativas de la madre; la ausencia de antecedentes familiares de lactancia; la ausencia de apoyo y soporte de la red. Conclusión: Amamantar es un fenómeno familiar y social, por lo que son necesarias prácticas promovedoras que extrapolen el binomio madre-bebé. En el proceso de cuidar se debe buscar la involucración de la dimensión social y subjetiva, mediante el fortalecimiento de la red de apoyo a las lactantes, a fin de lograrse prácticas profesionales más satisfactorias y promovedoras de la lactancia.

\section{DESCRIPTORES}

Lactancia Materna; Familia; Apoyo Social; Enfermería Maternoinfantil.

\section{REFERÊNCIAS}

1. Victora CG, Bahl R, Barros AJ, França GV, Horton S, Krasevec J, et al. Breastfeeding in the 21st century: epidemiology, mechanisms, and lifelong effect. Lancet. 2016;387(10017):475-90. DOI: 10.1016/S0140-6736(15)01024-7

2. Brasil. Ministério da Saúde. II Pesquisa de Prevalência de Aleitamento Materno nas Capitais Brasileiras e Distrito Federal [Internet]. Brasília; 2009 [citado 2018 out. 20]. Disponível em: http://bvsms.saude.gov.br/bvs/publicacoes/pesquisa_prevalencia_aleitamento_materno.pdf

3. Amorim STSP. Alimentação infantil e o marketing da indústria de alimentos: Brasil, 1960-1988. História Questões Debates [Internet]. 2005 [citado 2018 nov. 18];42(1):95-111. Disponível em: https://revistas.ufpr.br/historia/article/view/4638

4. Pérez-Escamilla, R. Amamentação no Brasil: grande progresso, quase um longo caminho pela frente. J Pediatr (Rio J) [Internet]. 2017 [citado 2018 nov. 18];93(2):107-10. Disponível em: http://www.scielo.br/scielo.php?pid=S0021-75572017000200107\&script=sci_arttext\&tlng=pt

5. Rollins NC, Bhandari N, Hajeebhoy N, Horton S, Lutter CK, Martines JC, et al. Why invest, and what it will take to improve breastfeeding practices? Lancet. 2016;387(10017):491-504. DOI: 10.1016/S0140-6736(15)01044-2

6. Boccolini CS, Boccolini PMM, Monteiro FR, Venâncio SI, Giugliani ERJ. Tendência de indicadores do aleitamento materno no Brasil em três décadas. Rev Saúde Pública [Internet]. 2017 [citado 2018 nov. 18];51:1-9. Disponível em: http://www.scielo.br/pdf/rsp/v51/pt_00348910-rsp-S1518-87872017051000029.pdf

7. Edwards ME, Jepson RG, Mcinnes RJ. Breastfeeding initiation: an in-depth qualitative analysis of the perspectives of women and midwives using Social Cognitive Theory. Midwifery. 2018;57:8-17. DOI: 10.1016/j.midw.2017.10.013

8. Yin RK. Estudo de caso: planejamento e métodos. $5^{\mathrm{a}}$ ed. Porto Alegre: Bookman; 2015.

9. Wright LM, Leahey M. Enfermeiras e famílias: um guia para a avaliação e intervenção na família. $4^{a}$ ed. São Paulo: Roca; 2008.

10. Primo CC, Brandão MAG. Interactive Theory of Breastingfeeding: creation and apllication of a middle-range theory. Rev Bras Enferm [Internet]. 2017 [cited 2018 Jan 08];70(6):1191-8. Available from: http://www.scielo.br/pdf/reben/v70n6/0034-7167-reben-70-06-1191.pdf

11. Wambach K, Domian EW, Page-Goertz S, Wurtz H, Hoffman K. Exclusive breastfeeding experiences among Mexican American women. J Hum Lact. 2016;32(1):103-11.

12. Rocci E, Fernandes RAQ. Dificuldades no aleitamento materno e influência no desmame precoce. Rev Bras Enferm [Internet]. 2014 [citado 2017 dez. 2];67(1):22-7. Disponível em: http://www.scielo.br/pdf/reben/v67n1/0034-7167-reben-67-01-0022.pdf

13. Halpern R, Coelho R. Excessive crying in infants. J Pediatr (Rio J). 2016;92(3 Suppl 1):S40-5. DOI: https://doi.org/10.1016/j.jped.2016.01.004

14. Organização Mundial da Saúde. Evidências científicas dos "Dez Passos para o Sucesso do Aleitamento Materno". Brasília: OMS; 2001.

15. Teles J, Bonilha A, Gonçalves A, Santo L, Mariot M. Amamentação no período de transição neonatal em Hospital Amigo da Criança. Rev Eletr Enf [Internet]. 2015 [citado 2017 nov. 02];17(1):94-9. Disponível em: https://www.fen.ufg.br/revista/v17/n1/pdf/v17n1a11.pdf

16. Briere CE, Mcgrath JM, Cong X, Brownell E, Cusson R. Direct-breastfeeding in the neonatal intensive care unit and breastfeeding duration for premature infants. Appl Nurs Res. 2016;32:47-51. DOI: 10.1016/j.apnr.2016.04.004

17. Brasil. Lei n. 13.257, de 08 de março de 2016. Dispõe sobre as políticas públicas para a primeira infância e altera a Lei no 8.069 , de 13 de julho de 1990 (Estatuto da Criança e do Adolescente), o Decreto-Lei no 3.689, de 3 de outubro de 1941 (Código de Processo Penal), a Consolidação das Leis do Trabalho (CLT), aprovada pelo Decreto-Lei no 5.452, de $1^{\circ}$ de maio de 1943, a Lei no 11.770 , de 9 de setembro de 2008, e a Lei no 12.662, de 5 de junho de 2012 [Internet]. Brasília; 2016 [citado 2019 abr. 18]. Disponível em: http://www.planalto. gov.br/ccivil_03/_Ato2015-2018/2016/Lei/L13257.htm

18. Brasil. Ministério da Saúde. Amamentação e uso de medicamentos e outras substâncias. 2a ed. Brasília: MS; 2014.

19. McClellan HL, Hepworth AR, Garbin CP, Rowan MK, Deacon J, Hartmann PE, et al Nipple pain during breastfeeding with or without visible trauma. J Hum Lact. 2012;28(4):511-21. DOI: 10.1177/0890334412444464

20. Moura LP, Oliveira JM, Noronha DD, Torres JDRV, Oliveira KCF, Teles MAB. Percepção de mães cadastradas em uma estratégia saúde da família sobre aleitamento materno exclusivo. Rev Enferm UFPE [Internet]. 2017 [citado 2017 out. 16];11 Supl. 3:1403-9. Disponível em: https://periodicos.ufpe.br/revistas/revistaenfermagem/article/viewFile/13983/16836

21. Pérez-Escamilla R. Síndrome de leche insuficiente. In: Martínez TGC, Cordero SH, editoras. Lactancia materna en México. Ciudad de México: Academia Nacional de Medicina; 2016.

22. Fallon V, Groves R, Halford JC, Bennett KM, Harrold JA. Postpartum anxiety and infant-feeding outcomes: a systematic review. J Hum Lac. 2016;32(4):740-58. DOI: 10.1177/0890334416662241

23. Darwent KL, McInnes R.J, Swanson V. The Infant Feeding Genogram: a tool for exploring family infant feeding history and identifying support needs. BMC Pregnancy Childbirth [Internet]. 2016 [cited 2017 Nov 01];16:315. Available from: https://www.ncbi.nlm.nih.gov/ pmc/articles/PMC5070085/ 
24. Fujimori E, Nakamura E, Gomes MM, Jesus LA, Rezende MA. Aspectos relacionados ao estabelecimento e à manutenção do aleitamento materno exclusivo na perspectiva de mulheres atendidas em uma unidade básica de saúde. Interface (Botucatu) [Internet]. 2010 [citado 2017 dez. 02];14(33):315-27. Disponível em: http://www.scielo.br/pdf/icse/v14n33/a07v14n33.pdf

25. Bai DL, TakFong DY, Lok KYW, Tarrant M. Relationship between the infant feeding preferences of Chinese mothers' immediate social network and early breastfeeding cessation. J Hum Lact. 2016;32(2):301-8. DOI: 10.1177/0890334416630537

26. Rodrigues AP, Padoin SMM, Guido LA, Lopes LFD. Fatores do pré-natal e do puerpério que interferem na autoeficácia em amamentação. Esc Anna Nery [Internet]. 2014 [citado 2017 dez. 02];18(2):257-61. Disponível em: http://www.scielo.br/pdf/ean/v18n2/1414-8145ean-18-02-0257.pdf

27. Sluzki CE. Personal social networks and health: conceptual and clinical implications of their reciprocal impact. Fam Syst Health. 2010;28(1):1-18. DOI: 10.1037/a0019061

28. Henderson J, Redshaw M. Midwifery factors associated with successful breastfeeding. Child Care Health Dev. 2011;37(5):744-53. DOI: 10.1111/j.1365-2214.2010.01177.x

29. Barnes M, Roiko A, Reed R, Williams C, Willcocks K. Experiences of birth and breastfeeding following assisted conception. Breastfeed Rev. 2013;21(1):9-15.

30. Sousa AM, Fracolli LA, Zoboli ELCP. Práticas familiares relacionadas à manutenção da amamentação: revisão da literatura e metassíntese. Rev Panam Salud Pública [Internet]. 2013 [citado 2017 dez. 01];34(2):127-34. Disponível em: https://scielosp.org/pdf/rpsp/2013. v34n2/127-134/pt

\section{ERRATA}

Na página 1, no nome dos autores:

Onde se lia:

Anna Chiesa ${ }^{3,1}$

Leia-se:

Anna Chiesa ${ }^{3}$

Rev Esc Enferm USP · 2020;54:e03662 